\title{
Contribution of the Freudian Theory of Psychosis in the Diagnosis of Mental Disorder
}

\author{
Claudia Henschel De Lima ${ }^{1,2,3}$ (i) \\ ${ }^{1}$ Graduate Program in Psychology, Universidade Federal do Rio de Janeiro, Rio de Janeiro, Brazil \\ ${ }^{2}$ Graduate Program in Public Administration (PROFIAP), Universidade Federal Fluminense. Volta Redonda, Rio de Janeiro, \\ Brazil \\ ${ }^{3}$ Psychology Department, Universidade Federal Fluminense, Volta Redonda, Rio de Janeiro, Brazil \\ Email: claudialima@id.uff.br
}

How to cite this paper: De Lima, C. H. (2021). Contribution of the Freudian Theory of Psychosis in the Diagnosis of Mental Disorder. Psychology, 12, 1259-1276. https://doi.org/10.4236/psych.2021.128079

Received: July 6, 2021

Accepted: August 16, 2021

Published: August 19, 2021

Copyright (c) 2021 by author(s) and Scientific Research Publishing Inc. This work is licensed under the Creative Commons Attribution International License (CC BY 4.0).

http://creativecommons.org/licenses/by/4.0/ (c) (i) Open Access

\begin{abstract}
The article presents my research in psychoanalytic psychopathology on the psychic etiology of psychosis, carried out between 2012 and 2020 at Universidade Federal Fluminense (Volta Redonda, Brazil). In Brazil, patients with various mental disorders rely on the Brazilian Unified Health System which aimed at treatment and psychosocial rehabilitation services. These services are called Psychosocial Care Centers (CAPS). There is an innovation in mental health treatment because they replace the treatment model for mental disorders directed only at hospital admissions. The clinical treatment of mental disorders in CAPS is organized into unique therapeutic projects. It is characterized by a multidisciplinary team in an open, non-hospital environment, close to the patient's place of residence. Since 1996, the SUS-Brazil diagnostic guidelines are used to conduct epidemiological studies, formulate public policies on mental health, and establish its funding for the mental health network. These manuals ignore the presence of etiological factors of a psychological nature and exclude the theoretical framework in the definition of disorders. The absence of consideration of etiological factors and the exclusion of theoretical frameworks is evident in the way the DSM-5 defines the spectrum of schizophrenia, resulting in the predominance of schizophrenia in the clarification of psychotic disorders and, consequently, in the weakening of the classic category of psychosis. My research aims to contribute to psychosis by examining the role of delusion in the onset of psychosis, triggering events, and stabilizing the psychotic structure. This article aims to present the hypothesis of the psychic etiology of psychosis from the contributions of Sigmund Freud. This theorizing is significant as it introduces the hypothesis of loss, restitution, and recovery into the psychiatric lexicon of the opposition between schizophrenia and paranoia. To this end, this article exhibits a survey of
\end{abstract}


Freudian references to emphasize the construction of an original theory of psychosis, where: 1) The consideration of the functioning of drives is relevant in isolating psychic etiology from its triggers; 2) A redefinition of the concept of delusion signals the originality of the Freudian theory of the stabilization of psychoses: delusion is defined as a psychic effort of recovery, an attempt at reaching a cure.

\section{Keywords}

Psychosis, Psychic Etiology, Delusion, Mental Health Policy, Psychoanalysis, Brazil

\section{Introduction}

The article presents my research in psychoanalytic psychopathology on the psychic etiology of psychosis, carried out between 2012 and 2020.

Mental disorders are a psychological pattern of clinical significance, usually associated with malaise or disability (Gomes et al., 2020). There are marked by changes in mood and thinking, behavioral changes associated with anxiety, distress, and deterioration of psychic and somatic functioning. Its clinical manifestations are varied, such as psychosis, disorders related to alcohol abuse and other drugs, depression, and bipolar disorder.

The World Health Organization (WHO) estimates that around 700 million people worldwide suffer from mental disorders. However, only a minority has adequate treatment for the disorders. Few countries have developed specific public policies for mental health, with a budget provided for by Law, political guidelines, and a forecast of the number of professionals to work in mental health institutions, according to data from WHO (2018), representing 1\% of total expenditures.

Mental disorders have a considerable impact on mental health services in Brazil. Data from the National Health Council in Brazil (CNS) reveal that 23 million people have some clinical manifestation of mental disorders, and 5 million of these Brazilians suffer from persistent and severe mental disorders.

Among the mental disorders, psychosis is a mental disorder with high morbidity, substantial functional impairments in terms of reduced psychomotor activity, affective blunting and cognitive degeneration, adequacy to work, and daily routines. In addition to this clinical picture, psychoses present hallucinations and delusional formations, which impair communication with family members or other people, contributing to the worsening of social isolation or the rupture of ties (Dalgalarrondo, 2019). These factors result in poor quality of life and demand specialized and continuous treatment.

In Brazil, patients with various mental disorders rely on the Brazilian Unified Health System (SUS-Brazil), aimed at treatment and psychosocial rehabilitation services. These services are called Psychosocial Care Center (CAPS). CAPS is an 
innovation in mental health treatment because they replace the treatment model for mental disorders directed only at hospital admissions.

The clinical treatment of mental disorders in CAPS is organized into unique therapeutic projects. It is characterized by a multidisciplinary team in an open, non-hospital environment, close to the patient's place of residence.

These therapeutic projects are based on the nosological classification of the International Classification of Diseases (ICD-10; World Health Organization, 1993) and the Diagnostic and Statistical Manual of Mental Disorders (DSM-5) (APA, 2013). Since 1996, the SUS-Brazil diagnostic guidelines are used to conduct epidemiological studies, formulate public policies on mental health, and establish its funding for the mental health network. Therefore, the DSM and the ICD are still relevant to:

1) Researching mental health in Brazil, focused on behavioral therapy for rehabilitating patients with mental disorders.

2) The formulation of public care policies for patients with mental disorders.

However, there is the exclusion of the theoretical framework in diagnosing mental disorders with significant losses in the clinical method and consequently, in the direction of mental disorders, especially psychosis.

However, the use of the ICD-10 and the DSM-5 represents a contradiction concerning the innovative model of psychosocial care, which was consolidated in Brazil as a replacement for the psychiatric hospitalization model. They are diagnostic manuals that provide physicians, psychologists, and mental health technicians with only a descriptive definition of mental disorders. These manuals ignore the presence of etiological factors of a psychological nature and exclude the theoretical framework in the definition of disorders. The absence of consideration of etiological factors and the exclusion of theoretical frameworks is evident in the way the DSM- 5 defines the spectrum of schizophrenia, resulting in the predominance of schizophrenia in the clarification of psychotic disorders and, consequently, in the weakening of the classic category of psychosis.

Even though the DSM-5 allows for greater precision in diagnosing schizophrenia, we observe in the clinical practice of the CAPS the increasing difficulty of physicians and psychologists in diagnosing psychosis without hallucinations and delusions and recognizing the clinical subtleties between schizophrenia and paranoia. These difficulties directly impact the relationship between diagnosis and direction of clinical treatment and the quality of treatment of psychotic patients. Moreover, they reflect the lack of research developed in modern psychiatry, not restricted to the ICD and the DSM, around the observation of the tendency of psychosis to become a typical clinical form, with a transition between the symptomatology of schizophrenia and the symptomatology of paranoia: in schizophrenia, affective and cognitive disorganization, positive intrusive symptoms and chronic withdrawal tend to evolve progressively and systematically, culminating in delusion (Stanghellini, 2009; Redmond, 2012).

My research aims to contribute to psychosis by examining the role of delusion in the onset of psychosis, triggering events, and stabilizing the psychotic struc- 
ture. This article aims to present the hypothesis of the psychic etiology of psychosis from the contributions of Sigmund Freud. This theorizing is significant as it introduces the hypothesis of loss, restitution, and recovery into the psychiatric lexicon of the opposition between schizophrenia and paranoia. In Psychoanalytic notes on an autobiographical account of a case of paranoia. (dementia paranoides) (2006 [1911]), Freud defended the hypothesis that if psychosis is characterized by a tendency towards the systematized form and the formation of delusion, then the clinical form of paranoia can be considered an attempt at restitution and stabilization when contrasted with schizophrenic withdrawal and disorganization. According to Freud (2006 [1911]), in paranoia, delusion is often correlated with the return of the subject's social relations with the world, albeit in a modified form. This hypothesis is very clear in The loss of reality in neurosis and psychosis (1924) when Freud defines that the reparative function of psychotic phenomena is mainly a response to the loss of reality that occurs when the subject rejects an element of the external world.

The collection of references I will discuss in this article demonstrate the originality that remains in the Freudian theory of psychosis in three conceptual axes:

1) The definition of psychosis in the perspective of the functioning of drives and not in the light of a break from objectifying reality.

2) The elaboration of a rejection process (Verwerfung) at the base of the establishment of a psychosis, conferring it the status of the logic of psychic functioning.

3) The repairing function of a delusion in a triggered psychosis.

The retelling of the Schreber case in this article aims at highlighting the Freudian project of elaborating a theory about the triggering of psychosis from the perspective of the theory of drives. It was Freud's reading of Memoirs of My Nervous Illness (1984 [1903]), written by President Daniel Paul Schreber, that gave him the necessary clinical material to find both the occurrence of a disturbance in the functioning of the drives, as well as a psychic effort of recovery in a psychosis, an attempt of reaching a cure through the delusion of being transformed into a woman.

\section{The Construction of the Freudian Theory of Psychosis}

Freud's conceptual work in understanding the psychic etiology of psychosis has its beginning in the letters exchanged with Fliess, indicating thus that his research regarding the etiology of psychic suffering extended beyond neurosis. In fact, from the time of the letters onwards, Freud conducted research on psychosis that was not guided by the description of the clinical presentation but by the search for the psychic process that created its symptoms. Even though his diagnostic technique followed the Kraepelian tradition in preserving the classes of paranoia, schizophrenia, mania, and melancholia, Freud breaks with the psychiatry of his time in considering the etiology of these clinical presentations from the perspective of the sexual cause, which he deduced from his clinical 
practice focused on hysterical neurosis, as we can verify in a commentary in Further remarks on the neuro-psychoses of defense (2006 [1896], p. 183): "The etiology of paranoia is to be found in the same sexual experiences of early childhood in which the etiology of hysteria and obsessional neurosis has already been discovered."

Firstly, the mixed status of the term psychoneurosis of defense is remarkable since it encompasses the neuroses and the psychoses. However, even though Freud had delineated neurosis and psychosis as clinical forms of the psychoneurosis of defense in his time, it is possible to delimit a conceptual effort involving the isolation of a specific defense process in psychosis. This is verified by using the term verwirft, which is used in a text predating 1896 entitled The Neuro-psychoses of defense (2006 [1894]).

Secondly, Freud's interest indicates the vectors of his etiological research: the conditions that explain the triggering of a psychosis follow the same logic proposed for the triggering of neurosis, the function of drives in early childhood. This definition cannot be separated from questioning the specificity of defense in neurosis and psychosis, as was discussed in The Neuro-psychoses of defense (2006 [1894]). Etiological research of psychosis should focus on the particular mode of psychic defense and the drive's objective (verwirft) that originates in the defense.

In The Pychoneurosis of defense (2006 [1894]), Freud defined neurosis and psychosis as clinical forms of the psychoneurosis of defense, considering them due to a defensive process directed towards a representation that is not compatible with the ego due to its traumatic and sexual nature. In this way, the specificity of the neurosis resides in the occurrence of defense against an incompatible sexual representation, causing the separation of the affection and preserving the most weakened representation in consciousness. Still, in the field of neuroses, Freud (2006 [1894]) differentiates their two clinical forms hysteria and obsession:

1) Hysteria: In hysteria, the affection, linked to the psychic representation, is removed, and a quantity of excitation that is not linked to the representation is transformed and used in another way, resulting in the conversion.

2) Obsession: The affection remains in the psychic sphere and is linked to other psychic representations.

Regarding defense in psychosis, Freud (2006 [1894]) considers its occurrence much more potent than in neuroses. Its specificity resides in the ego's energetic rejection (verwirft) of the psychic representation and the affection that is connected to it (without the separation of the representation and the affection, as happens in neuroses), resulting in the unawareness of the occurrence of the representation (as if it had never occurred) and the emergence of hallucinatory confusion.

In Draft G-Melancholia, of January $7^{\text {th }}, 1895$, Freud (2006 [1895a]), based on the specification of the process of defense in psychosis formulated in The Psychoneurosis of defense (2006 [1894]), described the etiology of melancholia, elaborating an essential hypothesis for the clinical recognition of its triggering: 
in the case of melancholy there occurs a retraction of the drives, and the melancholic experiences this retraction as a loss of libido. Thus, referring to the clinical example of anorexia, Freud (2006 [1895a]: p. 150) states that it consists of a melancholia: "The patient asserts that she has not eaten simply because she has no appetite and for no other reason. Loss of appetite, in sexual terms, loss of libido".

In Draft $H$-Paranoia, of January $24^{\text {th }}, 1895$, Freud (2006 [1895b]) extends the specification of the process of defense in psychosis to paranoia. He keeps his findings of 1894 regarding the functioning of defense in neuroses and psychoses and questions the possibility of the existence of a mode of functioning of the defense that is analogous in paranoia and obsession. Even though he recognized, for both psychoneurosis of defense, the occurrence of a rejection of an incompatible representation in regards to the ego, Freud (1895b/2006) isolated the psychic process specific to paranoia: the rejection of a representation that is not compatible with the ego and its projection onto the external world.

This specific logic of defense in paranoia is taken up again in the reasoning developed by Freud in Draft K (2006 [1896b]), where he isolated the mistrust of others as the primary symptom of paranoia and considered it a consequence of the aim of the drives in the process of defense.

In Further remarks on the neuro-psychoses of defense (2006 [1896]), Freud follows his researches of Drafts $G, H$, and $K$ regarding the specificity of the functioning of defense and emphasizes that the aim of the drive determines the symptom in psychoses. Returning to the psychic functioning of paranoia, he isolates three constituent phases according to the following schema:

Phase 1. A representation that is incompatible with the ego.

Phase 2. Rejection of an incompatible psychic representation and projection onto external reality.

Phase 3. Constitution of the primary symptom, mistrust of others.

What is notable in this ordering of the psychic process of paranoia, as shown in Further remarks on the neuro-psychoses of defense (2006 [1896]), is that these consecutive phases have as their central character an a posteriori effect produced by an external event, asserting how Freud articulates the process of the drives in childhood to a subsequent triggering occurrence.

Between 1896 and 1924, we can find three fundamental references regarding Freud's theories of psychosis: the first reference is the clinical monograph of the Schreber case, Psychoanalytic notes on an autobiographical account of a case of paranoia (dementia paranoides) (2006 [1911]). The second reference is On Narcissism: An Introduction (2006 [1914]), and the third is the article The Unconscious (2006 [1915]). They form the ground on which Freud would consolidate his theory of psychosis in 1924. From them, we can extract the following original statements:

1) The psychic process that constitutes a psychosis: “(...) that what was abolished internally returns from without” (Freud, 2006 [1911], p. 95). 
2) The relevance of determining the triggering conditions: the retraction of the drive regarding the investment in objects and people (Freud, 2006 [1914]).

3) The hypothesis of the occurrence of a loss of reality as a result of the emergence of neurosis and psychosis (Freud, 2006 [1914]; 2006 [1915]).

4) The emergence of the logic of hypochondriac phenomena in verbal expression, demonstrating its submission to the disruption of the functioning of the drives (Freud, 2006 [1914]; 2006 [1915]).

5) The recognition of the hegemony of the functioning of the drives in the etiology of the loss of reality which is seen in neuroses and psychoses, and the specificity of the role of delusion in psychoses: repairing the effects of the rejection of reality (Freud, 2006 [1924]).

As we will discuss in the following section of the article, the research regarding the peculiarity of Schreber's psychosis, the occurrence of a delusion of being transformed into a woman after the emergence of a clinical presentation of paranoid schizophrenia, led Freud to formulate an explanatory hypothesis for the triggering of the psychosis, that what was abolished internally (aufhebt) returns from without, and position the formation of delusion inside the framework of its triggering: delusion has a logic, and its place in psychic functioning is as an attempt of recovery from the effects of the process of rejection.

This theme of delusion returns indirectly in On Narcissism: An Introduction (2006 [1914]), where he established the clinical characteristics of schizophrenia and differentiated them from neurosis. Thus while in neurosis, the retraction of the investment of the drives occurs in fantasy. In the case of schizophrenia we have

1) A delusion of the end of the world: characterized by the retraction of the investment of the drives in things and people.

2) Megalomania (delusion of grandeur): characterized by the imaginary inflation of the ego, the positive pole of the retraction of the drives in psychosis.

3) Hypochondria: characterizes the most radical retraction of the drives to the level of the body.

Delusion is a process that can occur or not, and when it occurs, it possesses the primary function of repairing the investment of the drives in people and things.

In the text The Unconscious (2006 [1915]), Freud develops his research on the process of defense and, inside the theoretical framework of the metapsychological concept of the unconscious, conducts an investigative analysis of the distinction between hysteria and schizophrenia, parting from the viewpoint of the destiny that is assumed by the drives in the process of repression.

It is based on this conceptual reference that Freud discusses, in The Unconscious (2006 [1915]), the specificity of the defense process in psychoses and especially in the clinical form of schizophrenia: there we have the retraction of the investment of the drives in the object representations, and the advance onto the word representations. We wish to point out Freud's emphasis on the clinical ef- 
fect of this retraction on the field of verbal expression, which undergoes a disruption until it becomes completely incomprehensible. Referencing the case of Victor Tausk, Freud (2006 [1915]) identifies in his logic the exact structure of hypochondriac phenomena: "Here the schizophrenic utterance exhibits a hypochondriac trait: it has become 'organ-speech"' (Freud, 2006 [1915]: p. 226).

The hypotheses of the rejection of the psychic representation and retraction of the drives, formulated by Freud inside the first theory of drives, are not abandoned. However, they are considered in the light of the death drive from 1920 onwards. The crucial references to understand the development of a theory of the psychic processes that are specific to psychoses are the texts Neurosis and Psychosis (2006a [1924]) and The Loss of Reality in Neurosis and Psychosis (2006b [1924]). How do these two references articulate themselves in the direction of a definitive theory of the concept of rejection (Verwerfung)?

Freud (2006 [1924a]; 2006 [1924b]) states that neurosis and psychosis are an expression of the failure of the ego in reconciling the driving imperative (death drive) and the demands of civilization. In the case of a neurosis, the conflict between the driving imperative (death drive) and the demands of civilization is presented in the form of an impasse between the id and the ego, and the process of repression represents a solution, giving the psychic functioning a defense against the demands of the drives originating in the id. In the case of psychosis, the conflict appears in the form of an impasse between the ego and the external world.

The work on theories about the specificity of the psychic process that constitutes a psychosis is developed in The Loss of Reality in Neurosis and Psychosis (2006b [1924]). Based on the hypothesis of the distribution of the drives between the id, the ego, and reality, Freud expands on what was developed in Neurosis and Psychosis (2006a [1924]).

His theories consider that neuroses and psychoses configure different psychic processes but with similar results regarding the loss of reality. This leads in the text to the question about the status of the loss of reality in neuroses and psychoses regarding the specificity of the process of defense against the hegemony of the driving imperative: "Both neurosis and psychosis are thus the expression of a rebellion on the part of the id against the external world, of its unwillingness, or, if one prefers, its incapacity, to adapt itself to the exigencies of reality" (Freud, 2006 [1924b], p. 217).

Thus, the occurrence of the psychic processes of repression and rejection reveals the form in which the neurosis and the psychosis position themselves against the hegemony of the functioning of the drives: in the case of a neurosis, the ego, through repression, sacrifices a part of the imperative of the satisfaction of the drives (of the id) due to the demands of reality; in the case of psychosis the ego, being in service of the driving imperative, removes itself from a fragment of reality.

Both psychic processes result in a second phase when there is a loss of reality. In a neurosis, this loss is explained by the flight from the fragment of the per- 
son's reality due to whose demands repression was enacted; in the case of psychosis, it is explained by the creation of a delusion as a process of substitution of the rejected reality, as a patch put in place of reality. This hegemony thus explains the status of loss of reality: in neuroses, the resulting loss of reality is explained by the return of the imperative of the drives that was repressed; in psychoses, the loss of reality resides in the inflation of the imperative of the drives, which is manifested in its delusional logic of attempting to repair the rejected reality.

The references mentioned above make the originality of Freud's theory about psychoses in its three precise conceptual axes evident: regarding psychoses in the light of the functioning of the drives, elaborating a psychic process of rejection at the base of the composition of the psychosis, and the repairing function of delusion. These three axes clarify the etiology of the psychotic triggerings in the Schreber case and clarify the repairing status that his delusion of being transformed into a woman took regarding the hypochondriac phenomena suffered during the triggering of the psychosis.

\section{The Schreber Case in the Perspective of the Freudian Theory of Psychosis}

The clinical phenomenon of paranoia sits at the center of Freud's research into psychosis. Freud's monograph Psychoanalytic notes on an autobiographical account of a case of paranoia (dementia paranoides) (2006 [1911]), elaborated after he read the work Memoirs of My Nervous Illness (1984 [1903]), was considered the most relevant publication about the case of President Daniel Paul Schreber. Reading this work gave Freud the necessary clinical material to find they're not only the occurrence of a disturbance of the functioning of the drives in the psychosis but also the psychic work of recovery, an attempt at reaching a cure, through the delusion of being transformed into a woman, even before the theoretical formulations of 1924: "The delusional formation, which we take to be the pathological product, is, in reality, an attempt at recovery, a process of reconstruction" (Freud, 2006 [1911], pp. 94-95).

This formulation is evaluated as something that was never thought of in these terms before him, specifically before elaborating the concept of drives and the possibility of questioning the etiology of the triggering of psychosis in this light (Freud, 2006 [1911]).

As was mentioned before, Freud (2006 [1894]; 2006 [1895b]) initially defined paranoia as a psychoneurosis of defense, whose specificity in relation to neurosis resides in the prevalence of the psychic processes of rejection and projection. In fact, in Psychoanalytic notes on an autobiographical account of a case of paranoia (dementia paranoides), Freud (2006 [1911]) takes as his starting point the singularity of Daniel Paul Schreber's paranoid form of expression to sustain the etiological hypothesis of paranoia, based on the theoretical significance of the first theory of drives.

Freud's (2006 [1911]) hypothesis was thus elaborated to explain the cause of 
the psychotic experience of the breakdown of the world and its reconstruction: The activating cause of the triggering of paranoia is situated in the rejection of an idea that is intolerable to the ego and its projection into reality. More precisely, it is situated in the rejection of the manifestation of a libido such that "(...) what was abolished internally returns from without” (Freud, 2006 [1911], p. 95). Freud finds in Doctor Paul Flechsig, the doctor responsible for his treatment in the psychiatric hospital at the University of Leipzig, where he was first hospitalized in 1884, and in God the objects of the libido.

The hypothesis that what had been internally abolished returns from outside is unfolded in two phases to explain the process of the triggering of Schreber's psychosis. In the first phase, Schreber tended to relinquish pleasure and showed disbelief in God. In a second phase, which coincided with the triggering, Schreber surrendered to the sexual lust obtained in his specific relationship with God: He presented himself as a "Woman of God." Freud (2006 [1911]) also stated that the idea of being transformed into a woman is compensated by the delusion of grandeur of being the woman of God. In this way, basing himself on the pertinent findings of his first theory of drives and the theory of repression, Freud (2006 [1911]) elaborated a hypothesis about the psychic processes that are involved in the triggering of paranoia:

1) The retraction of the drives, previously invested in other people.

2) His fixation on narcissism.

3) The emergence of megalomania, which is typical in paranoia.

$\mathrm{He}$ also formulated an additional psychic process regarding the repression of the drives, named rejection (Verwerfung). This process explains, in the functioning of this grammar, how what has been internally rejected can return as if it came from outside. Thus, in formulating the aphorism of delusion as an attempt at solving the psychosis, as a way of reorganizing the psychic apparatus, Freud returns to the details of the case. Subsequently, we will present a synthesis centered on the main points regarding the triggering of the psychosis in the Schreber case.

\section{The Specificity of the Case}

Daniel Paul Schreber (1842-1911) was born in Leipzig on July $25^{\text {th }}, 1842$. He was the third of five children of the marriage of Daniel Gottlieb Moritz Schreber (orthopedic physician and educator) with Pauline Schreber, with his elder brother (Daniel Gustav) committing suicide at the age of 38, and only his older sister (Anna Jung) having children. His father's educational doctrine was rigid and moralistic, which can be inferred from his father's statements about childhood education (Schreber, 2000).

This moral rigidity had its objective of obtaining complete control over all aspects of life: from eating habits to spiritual life. Following this rigid doctrine, Daniel Gottlieb Moritz Schreber developed various orthopedic devices made of iron and leather to straighten the child's posture. There are reports that these devices resembled torture devices: the iron and leather used in its construction were assembled in such a way as to force the body to obtain the correct posture. 
These same methods were applied to his children, reinforcing thus the rigid and exaggerated aspect of Daniel Gottlieb Moritz Schreber's pedagogical procedures. No information was found on the personality of Schreber's mother and her role in the patient's childhood history. We only know that she was a woman of little affection, depressed and dominated by her husband.

Schreber started his studies in Law in 1860 and became a well-respected lawyer, marrying Sabine Beher in 1878. After their marriage, Schreber was nominated administrative director of the provincial tribunal of Chemnitz. In 1884, at the age of 41, he ran as a candidate for the Liberal National Party in the legislative elections in Chemnitz, defeated by the socialist Bruno Geiser.

As we can see in Table 1, the history of Schreber's triggerings was marked by his defeat in the Chemnitz elections in October 1884. At the time, he was already 42 years old and had had a career in Law for 19 years. A newspaper in Saxony published an article at this time about his defeat, entitled Who, after all, knows Dr. Schreber? This phase is particularly important because it evidences a central occurrence in triggering the hypochondriac presentation, which Schreber would experience afterward. On October $8^{\text {th }}$ of the same year, he suffered the first triggering, being interned in the Psychiatric Hospital of the University of Leipzig, where he would remain until June $1^{\text {st }}, 1885$.

During this stay, he met the director of the Leipzig Hospital, Doctor Paul Emil Flechsig, who played a fundamental role in the subsequent triggering of Schreber's clinical psychosis. Of his hospitalization in 1884, Schreber himself accounted for it being a very tiresome period, characterized by the clinical presentation of triggering described in Table 1. Returning to the publication of the article in the Saxonian newspaper, in light of the hypochondriac phenomena that were exhibited afterward, it is possible at this point to locate the occurrence of a central subjective experience caused by the title of the article (Who, after all, knows Dr. Schreber?), which affected Schreber as the weight of an enigma that was impossible to answer.

About this point, two references help clarify the enigmatic status that words and phrases assume in the psychotic experience. The first alludes to the consideration that follows the analysis of the Schreber case in The Unconscious (2006 [1915]), and the second refers to Jean-Claude Maleval's (1998) reference. Regarding Freud (2006 [1915]), the retraction of the investment of the drives in the object representations and the development of the word representations explain the triggering value of the phrase Who, after all, knows Dr. Schreber? who suffers from a derangement until the point that he becomes completely incomprehensible as if he were adrift.

Maleval's (1998) argument follows this orientation. He refers to Meyerson and Quercy, who, at the beginning of the $20^{\text {th }}$ century, described the subjective experience of the ineffable evil, which in these cases was immanent to the occurrence of words which broke the wider chain they were a part of and started functioning adrift, like painful enigmas. Maleval (1998) links the ineffable evil to the hypochondriac period experienced by specific subjects, identifying in these cases 
Table 1. Chronology of the circumstances of the triggering of Dr. Daniel Paul Schreber's psychosis, in the light of Freud's (1911/2006) formulation.

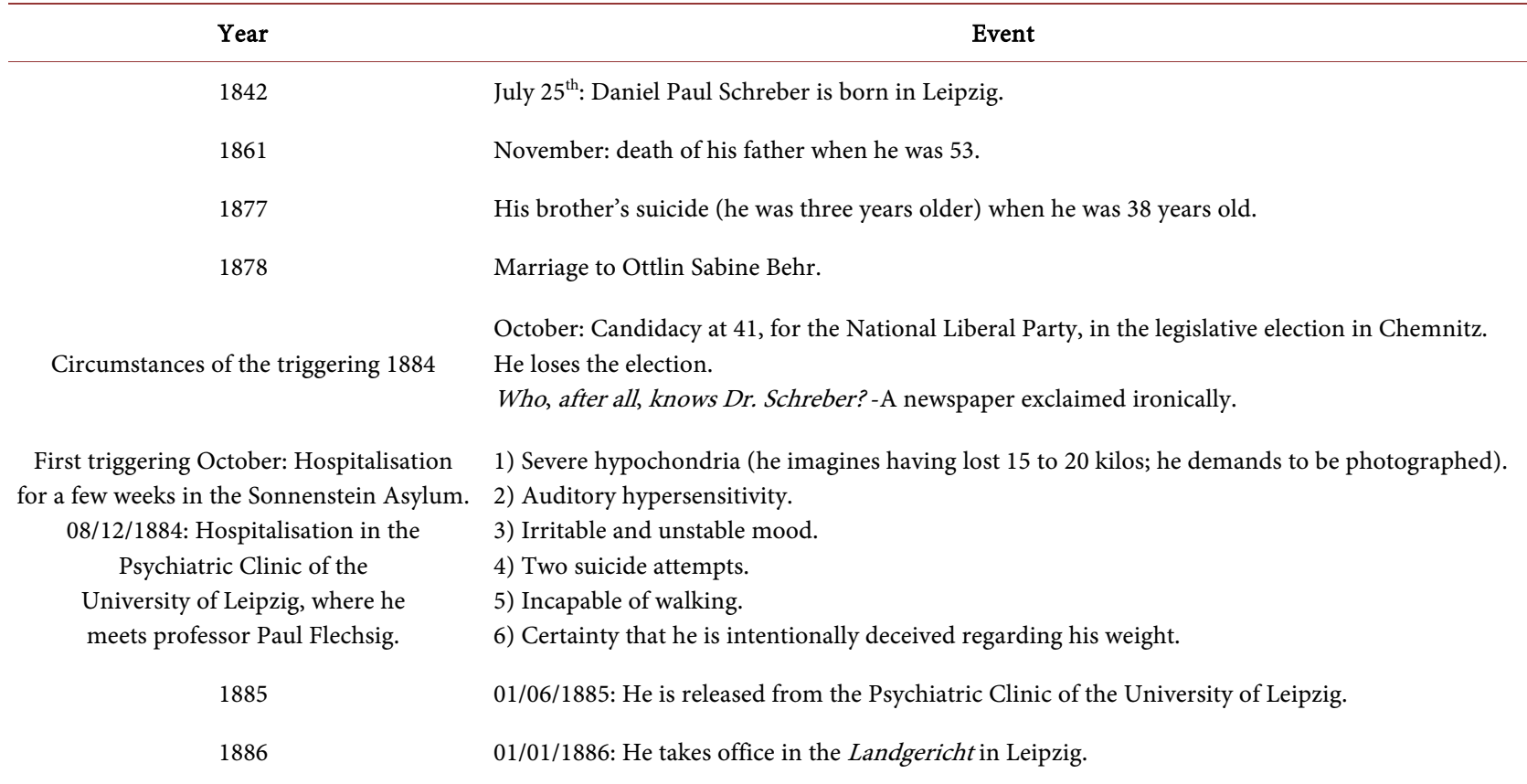

Circumstances of the triggering 1893.

June: At 50, he receives a nomination to be the Senatspräsident of the Dresden Appeals Court. Ottlin Sabine Behr's departure for health treatment.

01/10/1893: He takes office as the president judge of the Dresden Appeals Court.

He has a dream about the return of his illness/anxiety crises, production of fantasies in the hypnagogic state that it really must be very nice to be a woman submitting to the act of copulation.

1) Crises of anxiety and insomnia.

21/11/1893: Hospitalisation in the Psychiatric Hospital of the University of Leipzig.

1894

First triggering October: Hospitalisation for a few weeks in the Sonnenstein Asylum.

08/12/1884: Hospitalisation in the Psychiatric Clinic of the University of Leipzig, where he meets professor Paul Flechsig. 1885 1886

Circumstances of the triggering 1893.
2) Hypochondriac ideas with complaints about the softening of his brain, imminent death, hyperesthesia.

3) Ideas of persecution based on hallucinations; his thoughts, little by little, begin to revolve around visual and auditory hallucinations.

4) Hallucinatory stupor.

5) Experiences with a bodily influence where his body should be transformed into a woman's body and be copulated with: he was dead, suffered from a curse, was manipulated in a revolting way.

14/06/1894: Transference to the Lindehof Asylum.

29/06/1894: Transference to the Sonnestein Asylum worsening clinical presentation/temporary guardianship due to mental illness.

1) Severe hypochondria (he imagines having lost 15 to 20 kilos; he demands to be photographed).

2) Auditory hypersensitivity.

3) Irritable and unstable mood.

4) Two suicide attempts.

5) Incapable of walking.

6) Certainty that he is intentionally deceived regarding his weight.

01/06/1885: He is released from the Psychiatric Clinic of the University of Leipzig.

01/01/1886: He takes office in the Landgericht in Leipzig.

June: At 50, he receives a nomination to be the Senatspräsident of the Dresden Appeals Court. Ottlin Sabine Behr's departure for health treatment.

01/10/1893: He takes office as the president judge of the Dresden Appeals Court. 


\section{Continued}

21/11/1893: Hospitalisation in the Psychiatric Hospital of the University of Leipzig.

1894

Stabilization 1899/1901

1902

1903

Circumstances of the triggering 1907

Third triggering 1907
He has a dream about the return of his illness/anxiety crises, production of fantasies in the hypnagogic state that it really must be very nice to be a woman submitting to the act of copulation.

1) Crises of anxiety and insomnia.

2) Hypochondriac ideas with complaints about the softening of his brain, imminent death, hyperesthesia.

3) Ideas of persecution based on hallucinations; his thoughts, little by little, begin to revolve around visual and auditory hallucinations.

4) Hallucinatory stupor.

5) Experiences with a bodily influence where his body should be transformed into a woman's body and be copulated with: he was dead, suffered from a curse, was manipulated in a revolting way.

14/06/1894: Transference to the Lindehof Asylum.

29/06/1894: Transference to the Sonnestein Asylum worsening clinical presentation/temporary guardianship due to mental illness.

It was beginning of the process to recover his civil capacity.

1900: Writing of Memoirs of My Nervous Illness / unfavorable ruling regarding the request to suspend the guardianship/filing of an appeal.

1901: Writing of the supplement to Memoirs of My Nervous Illness.

14/07/1902: Suspension of the guardianship by the Appeals Court.

20/12/1902: Judicial decision of discharge.

Publication of Memoirs of My Nervous Illness through the publisher Oswald Mutze (Leipzig).

May: Death of his mother at 92.

November: Demands for the recognition of the "Schreber Associations" by its representatives.

14/11/1907: His wife has a crisis of aphasia due to a stroke.

14/11/1907: Anxiety crisis; insomnia; rigid gait and posture; auditory hallucinations and delusions; compulsive repetition $j a$... ja; he says he feels like someone wants to kill him.

27/11/1907: Internment at the Asylum in the village of Dösen, staying there until his death.

14/04/1911: Death at age 69 due to heart failure. Among the symptoms registered on his medical record were: laughing and shouting attacks, periods of depressive stupor, suicidal gestures, poor sleep, delusional ideas about his decomposition, and rotting.

the feeling of a lack of a foundation for being. Schreber's acute and severe hypochondria (with his demand of being photographed and his certainty of having lost weight), his feeling of weakness and being incapable of walking, and his two attempts at suicide demonstrate the lack of a foundation in his being and, consequently, his transformation of a question in a newspaper into an enigmatic experience: Who, after all, knows Dr. Schreber?

It is also interesting to discuss the problems caused by the enigmatic experience in psychosis, which was listed by Maleval (1998): What is the true organization of the universe? What is the nature of beings? What is the solution to the problem of creation? Which are the principles to reform society (or science, or religion, or Law)?

These problems appear clearly in chapters I and II of Memoirs of My Nervous Illness (2000), where the themes of God and Schreber's destiny are central, with a special emphasis on the hallucinations experienced by Schreber at the beginning of his triggering, which informed him that the cause could be in the murder of the soul that was committed in the $18^{\text {th }}$ century by one of Dr. Flechsig's ancestors. Returning to Schreber's clinical history after his discharge in 1885, he 
resumed his professional activities, holding various offices of being a district judge in Saxony. At this time, he was still profoundly grateful to Dr. Flechsig, to the point that Ottlin Sabine Behr kept the doctor's portrait on Schreber's desk for years. For eight years, Schreber did not present the signs of a triggering, being professionally successful. His only frustration resided in the fact of not having children.

In June 1893, when he was 50 years old, Schreber was appointed to the office of Senatspräsident of the third section of the Supreme Court of Appeals at Dresden. On October $1^{\text {st }}, 1893$, about four months after the appointment, he took the office of president of the senate. In this interval of four months, until he became president of the senate, he experienced many dreams and thoughts between sleep and waking that he had become sick again. Additionally, we observe the emergence of another triggering juncture in this interval marked by being nominated Senatspräsident, which was well identified by Freud: Ottlin Sabine Behr's brief departure to treat her health. She left her husband for four days, and when she returned, she found him in an altered state of turmoil, to the point of not wanting to see her again.

During these four days, Schreber had six nocturnal emissions and a thought, which occurred to him when he was half asleep: he thought that after all, it really must be very nice to be a woman submitting to the act of copulation (Freud, 2006 [1911], p. 61). When he analyzed this statement in Schreber's account, Freud (2006 [1911]) affirms that there was a libido development when Ottlin Sabine Behr was away for four days. The etiological hypothesis for the development of the libido is located by Freud in two events: the nomination to the office of Senatspräsident of the third section of the Supreme Court of Appeals at Dresden and the temporary absence of his wife. He discusses the context in which the triggering took place: Schreber's age (he was 51 years old and found himself in a critical phase in his sex life, similar to the feminine climacteric period); the transference (the feeling of sympathy for the doctor emerged from a process of transference of feelings towards someone that one day played an essential role in the patient's emotional life, in a context antecedent to the triggering of the psychosis); a deprivation (Schreber states that his marriage did not give him children).

The symptoms of anxiety and insomnia persist, and on November $21^{\text {st }}, 1893$, he is admitted for the second time to the Psychiatric Hospital in Leipzig. During this hospitalization, Schreber gave an account of the worsening of his state and a psychic change regarding Dr. Flechsig. In fact, during his whole process of triggering his paranoid psychosis, Schreber regards Dr. Flechsig in two different ways: as the murderer of the soul, being his only enemy; and as being responsible for the negative influence exerted onto God, who ceases being Schreber's ally and becomes the doctor's accomplice in a ploy to murder his soul and deliver his body as an object of sexual use.

Regarding the characteristics of his second triggering, Table 1 lists them synthetically: verbal hallucinations, experiences with a bodily influence, where his 
body should be transformed into the body of a woman and copulated with, religious and sexual delusions that involved being chosen and sent by God, being made pregnant by God to generate new humanity. Regarding the particular experiences with a bodily influence, Schreber recounts suffering from pain in almost every part of his body, with irreversible damage (his stomach and intestines were removed, his esophagus was dilacerated and his ribs were broken apart, he swallowed his larynx together with his food), indicating the radical aspect of the process of retracting the drives, with a catastrophic experience of the end of the world that is typical of a hypochondriac presentation and the decomposition of the functioning of the ego.

This experience of the end of the world is explained by Freud through the hypothesis of the retraction of the investment of the drives regarding the external world, in a way that this experience constitutes the actual projection of this catastrophic retraction, which affects his psychic functioning directly: "his subjective world has come to an end since the withdrawal of his love from it" (Freud, 2006 [1911], p. 94). It is the basis of the profound subjective disruption suffered in the triggering of the psychosis and witnessed in the form of ideas such as the catastrophe of the world and a corpse that carries another corpse (Schreber 2000). However, Freud finds the emergence of the second phase in Schreber's psychosis, which is composed by the appearance of a delusion that emerges to repair the catastrophic process of retracting the drives, in comparison with the first phase, where the retraction of the investment of the drives in objects and people is paramount. There is an experience of the end of the world:

Moreover, the paranoic build it again, not more splendid, it is true, but at least so that he can once more live in it. He builds it up by the world of his delusions. The delusional formation, which we take to be the pathological product, is, in reality, an attempt at recovery, a process of reconstruction. Such a reconstruction after the catastrophe is successful to a greater or lesser extent, but never wholly so; there has been a 'profound internal change' in the world, in Schreber's words. However, the human subject has recaptured a relation, and often a very intense one, to the people and things in the world, even though the relationship is a hostile one now, where formerly it was hopefully affectionate (Freud, 2006 [1911], pp. 94-95).

In Schreber's case, in this second phase, or the culminating point of the patient's delusional system, there is a development of the delusion of being transformed into a woman. This delusion restores the investment of the drives through the possibility of giving birth, by divine intervention, to a new generation that will save humanity, what Freud (2006 [1911], p. 27) saw in Schreber as being the mission to redeem the world and to restore humankind to their lost state of bliss.

According to Freud's (2006 [1911]) hypothesis, the objective of the delusion is to transform into a woman acceptable. He finds in Schreber's testimony the exact moment of this personal change. It can be found in November 1895, when 
Schreber had started the process of coming to terms with the idea of the transformation, harmonizing it with God's most elevated designs: "He took up a feminine attitude towards God; he felt that he was God's wife" (Freud, 2006 [1911], p.49).

Thus, the two constituent phases of psychosis, retraction of the investment of the drives and delusional reconstruction, establish the originality and specificity of the etiological hypothesis of psychoses: “(...) what was abolished internally returns from without” (Freud, 2006 [1911], p. 95). This hypothesis would return thirteen years later, in 1924, and it allowed Freud (2006 [1924]) to conclude that, when conducting etiological research, in the case of neuroses as well as psychoses, it is crucial to examine not only the status of the loss of reality but also its reconstruction.

\section{Conclusion}

This article aims to present the hypothesis of the psychic etiology of psychosis from the contributions of Sigmund Freud. The article examined delusion in the onset of psychosis, triggering events, and stabilizing the psychotic structure. By investigating the hypothesis of loss, restitution, and recovery into the psychiatric lexicon of the opposition between schizophrenia and paranoia, I set out to elucidate the mechanisms underlying the onset of psychosis and triggering events in psychosis. Therefore, the article exhibited a critical overview of Freudian references in order to show the development of a novel theory of psychosis in the field of psychiatry in three precise conceptual axes:

1) The consideration of psychosis in the light of the functioning of drives and not in the light of a break from objectifying reality.

2) The elaboration of a rejection process at the basis of establishing a psychosis, conferring it the status of the logic of psychic functioning.

3) The repairing function of a delusion in a triggered psychosis.

This development was ethically aligned with psychoanalysis' implications regarding its understanding of the diagnosis of psychosis, in particular from the advances of modern psychiatry regarding the tendency of psychosis to become a typical clinical form, with a transition between the symptomatology of schizophrenia and the symptomatology of paranoia. My research demonstrates how Freud's thought brings, even today, significant contributions to this theme. The teaching of the Freudian theory of psychosis in psychopathology can contribute to qualified training in psychiatry and psychoanalysis, which prepares professionals for the recognition of psychosis, the mapping of triggering situations, and assisting patients in constructing strategies for stabilization.

In Brazil, psychoanalysis contributes to mental health policy because its theory on the psychic etiology of psychosis is in line with the psychosocial treatment and rehabilitation process defined by the therapeutic projects.

Finally, when the academic training of physicians and psychologists for the clinical approach of psychotic patients is directed towards abrupt diagnoses and 
brief treatments aimed at social rehabilitation, the fundamental role of psychoanalysis consists precisely in elucidating what happens in the field, from psychosis, when the obsession with describing abnormal behavior dominates the current situation and deafens clinical practice to the suffering of those who seek it.

\section{Conflicts of Interest}

The author declares no conflicts of interest regarding the publication of this paper.

\section{References}

American Psychiatry Association (APA) (2013). Diagnostic and Statistical Manual of Mental Disorders-DSM V(5 ed.). Washington DC.

Dalgalarrondo, P. (2019). Psicopatologia e semiologia dos transtornos mentais. Porto.

Freud, S. (1894). As neuropsicoses de defesa. In S. Freud (Ed.), Brazilian Standard Edition of the Complete Works of Sigmund Freud (pp. 57-88). Translated from English by Luis Alberto Hanns, 2006, vol. 3, Imago Editora.

Freud, S. (1895a). Rascunho G. In S. Freud (Ed.), Brazilian Standard Edition of the Complete Works of Sigmund Freud (pp. 260-261). Translated from English by Luis Alberto Hanns, 2006, vol. 1, Imago Editora.

Freud, S. (1895b).Rascunho H. In S. Freud (Ed.), Brazilian Standard Edition of the Complete Works of Sigmund Freud (pp. 262-263). Translated from English by Luis Alberto Hanns, 2006, vol. 1, Imago Editora.

Freud, S. (1896a). Observações adicionais sobre as neuropsicoses de defesa. In S. Freud (Ed.), Brazilian Standard Edition of the Complete Works of Sigmund Freud (pp. 187-216). Translated from English by Luis Alberto Hanns, 2006, vol. 3, Imago Editora.

Freud, S. (1896b). Rascunho K. In S. Freud (Ed.), Brazilian Standard Edition of the Complete Works of Sigmund Freud (pp. 270-273). Translated from English by Luis Alberto Hanns, 2006, vol. 1, Imago Editora.

Freud, S. (1911). Notas psicanalíticas sobre um relato autobiográfico de um caso de paranoia (dementia paranoides). In S. Freud (Ed.), Brazilian Standard Edition of the Complete Works of Sigmund Freud (pp. 23-110). Translated from English by Luis Alberto Hanns, 2006, vol. 12, Imago Editora.

Freud, S. (1914). Sobre o Narcisismo: Uma Introdução. In S. Freud (Ed.), Brazilian Standard Edition of the Complete Works of Sigmund Freud (pp. 89-122). Translated from English by Luis Alberto Hanns, 2006, vol. 14, Imago Editora.

Freud, S. (1915). O Inconsciente. In S. Freud (Ed.), Brazilian Standard Edition of the Complete Works of Sigmund Freud (pp. 191-252). Translated from English by Luis Alberto Hanns, 2006, vol. 14, Imago Editora.

Freud, S. (1924a). Neurose e Psicose. In S. Freud (Ed.), Brazilian Standard Edition of the Complete Works of Sigmund Freud (pp. 189-198). Translated from English by Luis Alberto Hanns, 2006, vol. 19, Imago Editora.

Freud, S. (1924b). A Perda da Realidade na Neurose e na Psicose. In S. Freud (Ed.), Brazilian Standard Edition of the Complete Works of Sigmund Freud (pp. 229-238). Translated from English by Luis Alberto Hanns, 2006, vol. 19, Imago Editora.

Gomes, C. F. M., Pereira Junior, R. J., Cardoso J. V., \& Silva, D. A. (2020). Common Mental Disorders in University Students: Epidemiological Approach about Vulnerabilities. SMAD, Revista Eletrônica de Saúde Mental, Alcool e Drogas, 16, 1-8. 
https://doi.org/10.11606//issn.1806-6976.smad.2020.157317

Maleval, J. C. (1998). Lógica del Delirio. Ediciones del Serbal.

Redmond, J. (2012). Elementary Phenomena, Body Disturbances, and Symptom Formation in Ordinary Psychosis. Submitted in Fulfillment of the Requirements for the Degree of Doctor of Philosophy, Deakin University.

Schreber, D. P. (2000). Memoirs of My Nervous Illness. New York Review Books.

Stanghellini, G. (2009). Embodiment and Schizophrenia. World Psychiatry, 1, 56-59. https://doi.org/10.1002/j.2051-5545.2009.tb00212.x

WHO (2018). Mental Health Atlas 2017. World Health Organization. 